\title{
Bronchoscopic surfactant administration preserves gas exchange and pulmonary compliance after single lung transplantation in dogs
}

\author{
Ivar Friedrich, $\mathrm{MD}^{\mathrm{a}}$ \\ Jochen Börgermann, $M D^{a}$ \\ Fred H. Splittgerber, $M D^{\mathrm{b}}$ \\ Matthias Brinkmann, $\mathrm{MD}^{\mathrm{b}}$ \\ J. Christoph Reidemeister, $M D^{\mathrm{b}}$ \\ Rolf E. Silber, MD ${ }^{\mathrm{a}}$ \\ Werner Seeger, MD ${ }^{c}$ \\ Reinhold Schmidt, $\mathrm{PhD}^{\mathrm{c}}$ \\ Andreas Günther, $\mathrm{MD}^{\mathrm{c}}$
}

\section{See related article on page 344 .}

From the Department of Cardiothoracic Surgery, ${ }^{a}$ Martin Luther University, Halle, Germany; Department of Thoracic and Cardiovascular Surgery, ${ }^{\mathrm{b}}$ University Essen, Essen, Germany; and Department of Internal Medicine, ${ }^{\mathrm{c}}$ Justus Liebig University, Giessen, Germany.

The study was supported by the Hans und Gertie Fischer Stiftung für Herz- und Kreislaufforschung (Mühlheim/Ruhr, Germany).

Received for publication Aug 12, 2002; revisions received Sept 27, 2002; accepted for publication Oct 18, 2002 .

Address for reprints: Dr Ivar Friedrich, Department of Cardiothoracic Surgery, Martin Luther University, Ernst Grube Str 40, D-06097 Halle, Germany (E-mail: ivar.friedrich@medizin.uni-halle.de).

J Thorac Cardiovasc Surg 2004;127:335-43 $0022-5223 / \$ 30.00$

Copyright $\odot 2004$ by The American Association for Thoracic Surgery

doi:10.1016/j.jtcvs.2002.10.001
Background: Surfactant abnormalities have been implicated in reperfusion injury and respiratory failure in lung transplantation.

Methods: We investigated the efficacy of bronchoscopic administration of a bovine natural lung surfactant extract (Alveofact) to improve gas exchange and lung mechanics after heterologous left lung transplantation in foxhounds $\left(+4^{\circ} \mathrm{C}\right.$ ischemia for 24 hours, conservation with Euro-Collins solution). Animals received either no surfactant therapy (untreated controls, $\mathrm{n}=6$ ) or $50 \mathrm{mg} / \mathrm{kg}$ body weight (prior to explantation, only graft) and $200 \mathrm{mg} / \mathrm{kg}$ body weight Alveofact (immediately after reperfusion, both lungs, $n=6$ ). After lung transplantation, separate but synchronized ventilation of each lung was performed in a volume-controlled, pressurelimited mode for 12 hours, with the animals prone. Small catheters were inserted into the pulmonary veins of both the graft and the recipient's native lung for separate blood gas analysis. In the control group, marked protein leakage, influx of neutrophils into the alveolar space, and pulmonary edema formation (extravascular lung water; wet/dry ratio) were encountered in the transplanted lung but only to a very minor extent in the recipient's native lung.

Results: Lung compliance values and arterial oxygenation progressively deteriorated in the transplanted but not in the native lungs. Pulmonary hemodynamics did not change significantly. Surfactant administration did not significantly influence the development of reperfusion edema, protein leakage, and neutrophil influx into the grafts. However, surfactant restored the surface activity and the gas exchange $\left(\mathrm{PaO}_{2} / \mathrm{FIO}_{2}\right.$ of $201.2 \pm 20.2 \mathrm{~mm} \mathrm{Hg}$ vs $119.8 \pm 21.7 \mathrm{~mm} \mathrm{Hg}$ in controls; $\left.P<.05\right)$ in the transplanted lungs, and compliance was markedly improved in the surfactant-treated animals $(18.8 \pm 1.8 \mathrm{~mL} / \mathrm{mbar}$ vs $11.5 \pm 1.6 \mathrm{~mL} / \mathrm{mbar}$ in the controls; $P<.05)$.

Conclusion: Bronchoscopic surfactant administration does not prevent leukocyte influx or vascular leakage but does protect against respiratory failure and improves lung mechanics in single lung transplantation in dogs.

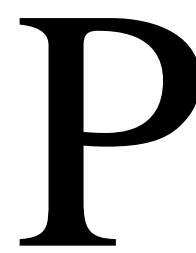
ulmonary edema formation with progressive worsening of gas exchange and lung mechanics, commonly referred to as "ischemiareperfusion injury," is a frequent and feared complication in lung transplantation. ${ }^{1}$ The pathophysiological abnormalities encountered under these conditions resemble typical features of the adult respiratory distress syndrome (ARDS) and include a high alveolar protein and fluid burden, a pronounced influx of inflammatory cells (mostly neutrophils) 
TABLE 1. Warm, cold, and total ischemic time of the transplanted lungs

\begin{tabular}{lccc}
\hline & $\begin{array}{c}\text { Warm ischemic time } \\
\text { (minutes) }\end{array}$ & $\begin{array}{c}\text { Cold ischemic time } \\
\text { (minutes) }\end{array}$ & $\begin{array}{c}\text { Total ischemic time } \\
\text { (minutes) }\end{array}$ \\
\hline Control $(\mathrm{n}=6)$ & $54.3 \pm 8.2$ & $1436.7 \pm 59.2$ & $1487.0 \pm 58.1$ \\
Surfactant $(\mathrm{n}=6)$ & $50.3 \pm 3.3^{*}$ & $1443.3 \pm 60.3 \dagger$ & $1497.7 \pm 60.9 \ddagger$ \\
\hline
\end{tabular}

Given are the mean \pm SEM of the warm ischemic time (preparation and implantation), the cold ischemic time (flush preservation until take out of the sterile bag), and the total ischemic time (sum of both). Statistical niveau between control (not treated) and surfactant (surfactant treatment) as stated in the table. ${ }^{*} P=.44$

$\dagger P=.94$.

$\ddagger P=.90$.

into the alveolar compartment, and increased local and systemic levels of proinflammatory cytokines (tumor necrosis factor-alpha, interleukin-6, interleukin-8).

Transbronchial surfactant administration has been shown to improve gas exchange in a large body of experimental ARDS models and in patients suffering from severe ARDS. ${ }^{2}$

In view of the similarities between reperfusion injury and ARDS, it has been speculated that changes in the function of the pulmonary surfactant system might also be operative under conditions of pulmonary ischemia-reperfusion. Surfactant administration after lung transplantation was firstly suggested by Novick and colleagues ${ }^{3}$ in 1991 . During the following years a considerable number of experimental studies have been published to verify the benefit of surfactant treatment in reperfusion injury. Natural surfactant preparations were used in different animal models such as canine, minipigs, and rats. ${ }^{4-9}$

A detailed analysis of the biochemical and biophysical surfactant properties in canine lungs undergoing 24 hours of cold ischemia and 12 hours of reperfusion was undertaken and the occurrence of severe surfactant abnormalities in the reperfusion period was demonstrated, as reported in the companion article. ${ }^{9 a}$ The studies were performed under conditions of separate but synchronized ventilation of the transplanted (single) lung and the native lung to avoid tidal volume shift between the graft and the native lung, which may otherwise give way to the appearance of ventilatorinduced lung injury (VILI). ${ }^{10}$ We report on the impact of bronchoscopic surfactant administration on the development of posttransplantation lung injury. This maneuver was found to not affect pulmonary edema formation and neutrophil influx into the alveolar space but it strongly antagonized the loss of compliance and the deterioration of gas exchange in the transplanted lungs. Administration of surfactant to lungs subjected to severe ischemia-reperfusion may thus be suggested as a useful therapeutic regimen to improve posttransplantation lung function.

\section{Methods}

\section{Materials and Methods}

Calf lung surfactant extract (Alveofact) was a generous gift from Dr H. Weller (Thomae, Biberach, Germany); this material is widely used for infant respiratory distress syndrome (IRDS) treatment and has also been investigated in a pilot study for treatment of ARDS. Euro-Collins solution was a generous gift from Fresenius, Bad Homburg, Germany. Anesthesia was induced by injection of thiopentone (Altana Pharma, Konstanz, Germany), fentanyl (Curamed Pharma $\mathrm{GmbH}$, Karlsruhe, Germany), and rocuronium (Organon Teknika, Boxtel, NL) and was maintained by a continuous infusion of midazolam hydrochloride (Hoffmann LaRoche AG, Grenzach Wyhlen, Switzerland). Flolan (100 $\mu \mathrm{g} / \mathrm{L}$; Wellcome, Greenford, UK) was added to the Euro-Collins solution.

\section{Transplantation Model}

Heterologous left lung transplantation was performed in foxhounds (12 donors, 12 recipients, both sexes, $27-33 \mathrm{~kg}$, weightmatched) with the approval of the local authorities. The animals were randomly assigned to the control group $(n=6)$ and the surfactant group $(\mathrm{n}=6)$. The animals received full care according to the Principles of Laboratory Animal Care (National Institutes of Health publication no. 85-23, revised 1985) and were allowed water and food ad libitum until 12 hours prior to surgery. None of the animals showed any signs of infection, as based on body temperature, peripheral blood counts, and lung auscultation. All experimental and surgical approaches were performed under sterile conditions by 1 cardiothoracic surgeon. The animals did not develop fever, and blood cultures obtained at 6 and 12 hours postreperfusion were all sterile. All animals remained hemodynamically stable; there was no need for catecholamine administration during surgery or the postoperative course. Volume (Ringer's lactate) was substituted depending on central venous $(<8 \mathrm{~mm} \mathrm{Hg})$ and mean arterial $(<60 \mathrm{~mm} \mathrm{Hg})$ pressures. There was no difference in warm ischemic time between the groups (Table 1).

\section{Ventilation Patterns}

After reperfusion both lungs were independently ventilated using 2 Evita II ventilators (Dräger, Lübeck, Germany) in a master and slave mode. Two tracheal tubes (both 9-mm internal diameter) were inserted, 1 into the left and 1 into the right main bronchus, and the left bronchus was snared tightly around the tracheal tube. The tube placed to the right bronchus had its balloon cuff inflated near the tracheal bifurcation (while it was avoided) to cover the ostium of the upper lobe bronchus. The right lung received $60 \%$ and the left lung $40 \%$ of the entire tidal volume, which was started with $14 \mathrm{~mL} / \mathrm{kg}$ body weight (BW) and then adjusted to maintain normocapnia in lung veins to either side, and was then left unchanged for the remainder of the experiment. Ventilator frequency 
was set to $10 \times / \mathrm{min}$, an upper pressure limit of $30 \mathrm{~mm} \mathrm{Hg}, \mathrm{FIO}_{2}$ of 0.5 , and positive end-expiratory pressure (PEEP) of $5 \mathrm{~cm} \mathrm{H}_{2} \mathrm{O}$ for the duration of the experiment. Under these conditions, normocapnia was obtained.

\section{Donor Procedure}

After intravenous anesthesia with thiopentone (30 mg/kg BW) and oropharyngeal intubation, the animals were ventilated at a frequency of $10 \times / \mathrm{min}$, with an $\mathrm{FIO}_{2}$ of 0.5 , in a volume-controlled (tidal volume $14 \mathrm{~mL} / \mathrm{kg} \mathrm{BW})$, pressure-limited $\left(\mathrm{p}_{\max }=30 \mathrm{~mm}\right.$ $\mathrm{Hg}$ ) fashion (Evita II, Dräger). Tidal volume was adjusted to maintain $\mathrm{paCO}_{2}$ values between 35 and $40 \mathrm{~mm} \mathrm{Hg}$. Anesthesia was maintained with fentanyl $(0.7 \mathrm{mg} / \mathrm{h})$, midazolam $(5 \mathrm{mg} / \mathrm{h})$, and rocuronium $(15 \mathrm{mg} / \mathrm{h})$ via continuous infusion, and an extra 1.5-mg dose of fentanyl was administered for thoracotomy. Left lateral thoracotomy was performed through the fifth intercostal space. After the pericardium was opened and the great vessels were dissected, a large-bore line was inserted into the pulmonary artery. In the surfactant group, $50 \mathrm{mg} / \mathrm{kg}$ BW Alveofact was instilled by bronchoscopic technique in 10 divided doses into each segment of the left lung. No transbronchial fluid administration was performed in the control group. Immediately after opening of the left atrial appendage, $60 \mathrm{~mL} / \mathrm{kg}$ of cold, modified Euro-Collins solution (including $100 \mu \mathrm{g} / \mathrm{L}$ prostaglandin $\mathrm{E}_{2}$ ) were infused through the pulmonary arterial line at a temperature of $4{ }^{\circ} \mathrm{C}$ and under a pressure of $30 \mathrm{~cm} \mathrm{H}_{2} \mathrm{O}$. The lungs were ventilated throughout the preservation period. At the end of the washout procedure, the lungs were inflated to a pressure of $20 \mathrm{~cm} \mathrm{H}_{2} \mathrm{O}$ and the trachea was stapled. The heart-lung block was then excised, packed into sterile bags, and stored swimming in $4^{\circ} \mathrm{C}$ water in a refrigerator for 24 hours.

\section{Recipient Procedure}

Anesthesia and ventilation were identical as described for the donors, as was left lateral thoracotomy. The left-sided lung vessels were dissected and right lung ventilation was established; the pulmonary artery was clamped with a bulldog clamp and the bronchus with an atraumatic clamp. After heparinization $(50 \mathrm{U} / \mathrm{kg}$ BW) a Cooley clamp was positioned to truncate the pulmonary veins at the level of the left atrium, cutting the tissue bridge to create an opening for the left atrial cuff anastomosis of the donor lung. The donor heart-lung block was taken from the storage bag, and the left lung was prepared with a remainder of left atrial cuff containing the left pulmonary veins. Implantation sequence was left atrial cuff with 7-0 Prolene suture (Ethicon, Norderstedt, Germany), left bronchus anastomosis with 4-0 Cardiofil (BraunDexon, Tuttlingen, Germany) running suture, and the left pulmonary artery with 7-0 running Prolene suture. Total time from the end of cold ischemia period until reperfusion was identical for both groups (Table 1). The preserved and stored but not transplanted right donor lung was lavaged ex situ to assess storage-induced changes. After completion of left lung transplantation, a second tracheal tube ( $9 \mathrm{~mm}$ internal diameter) was positioned in the left main bronchus of the graft and secured tightly, thus allowing separate ventilation of the graft and the native lung as previously described. Upon ventilation of the graft, reperfusion was started and time was set to zero. Next, 2 small catheters were placed into the pulmonary veins of the left and the right lower lobes for withdrawal of blood samples. After insertion of a chest tube and wound closure, the animals were positioned on a vacuum-mattress and remained in the prone position until the end of the observation period (12 hours).

In the surfactant group, a second dose $(200 \mathrm{mg} / \mathrm{kg} \mathrm{BW})$ of Alveofact was administered bronchoscopically in divided doses into each segment of both lungs, as soon as the animals were in the prone position. No transbronchial administration of fluids was performed in the control group. The animals were sacrificed by exsanguination. Both lungs were excised and samples for wet-todry ratio were taken from the left and right lower lobe.

\section{Lung Function}

Central venous, arterial, and left and right pulmonary venous blood samples were withdrawn hourly to determine hemoglobin, potassium, and blood gases (blood gas analyzer ABL 4, Radiometer, Copenhagen, Denmark). Similarly, dynamic compliance, mean and peak ventilation pressures, as well as tidal and minute volume were read from the respirator once an hour.

\section{Hemodynamic Monitoring}

A femoral artery and a pulmonary artery catheter (Swan Ganz, Baxter Healthcare, Irvine, Calif) for characterization of pulmonary and systemic hemodynamics and blood sampling were placed percutaneously; pressure transducers (Millar Micro Tip, Millar Instruments Inc, Houston, Tex) were positioned at mid-heart level and referenced to the atmospheric pressure level to record mean arterial pressure, mean pulmonary arterial pressure, central venous pressure (CVP), and pulmonary capillary wedge pressure (PCWP). Using a Sirecust 9000 Monitor (Siemens Medical Products, Erlangen, Germany), cardiac output was assessed by thermodilution. Cardiac index (CI), pulmonary vascular resistance index, and systemic vascular resistance index were calculated by standard formula. The body surface area (BSA) was estimated as follows: BSA $\left(\mathrm{m}^{2}\right)=\left(0.1 \cdot(\mathrm{kg} \text { body weight })^{2 / 3}\right)$.

\section{Measurement of Pulmonary Fluid Accumulation}

Two different techniques were employed. (1) The wet-to-dry ratio was determined on all excised lungs. Three lung slices, all obtained from the upper lobe, were weighed immediately after harvesting and after reaching complete dryness $\left(65^{\circ} \mathrm{C}\right.$ for 14 days $)$. (2) Extravascular lung water (EVLW) was determined by means of a thermo-dye dilution technique (COLD Z-0-21 Monitor, Pulsion Medical Systems, Munich, Germany). ${ }^{11}$ For this purpose, an additional arterial thermistor-tipped fiberoptic catheter (Pulsiocath 4F FT PV 2024, Pulsion Medical Systems) was inserted into the femoral artery. CI, extravascular lung water index (EVLWI), and intrathoracic blood volume index (ITBVI) were determined in triplicate by injecting $8 \mathrm{~mL}$ of ice-cooled indocyanine green (ICG; $1 \mathrm{mg} / \mathrm{mL}$; Pulsion Medical Systems) via the central venous line. With the thermo-dye dilution technique, ITBV and EVLW were calculated as: ITBVI $=\mathrm{CI} \cdot \mathrm{MTt}_{\mathrm{ICG}}$, where $\mathrm{MTt}_{\mathrm{ICG}}$ is the mean transit time of indocyanine green, and EVLWI $=\left(\mathrm{CI} \cdot \mathrm{MT}_{\text {therm }}\right)-$ ITBV, where $\mathrm{MT}_{\text {therm }}$ is the mean thermal transit time. EVLWI was assessed at baseline (induction of anesthesia) and 1, 3, 6, 9, and 12 hours after reperfusion.

\section{Bronchoalveolar Lavage}

Bronchoalveolar lavage fluid (BALF) was collected either in vivo by flexible bronchoscopy (Olympus BF P-10 bronchoscope, 
TABLE 2. BALF protein content and neutrophil counts

\begin{tabular}{|c|c|c|c|c|}
\hline & \multirow[b]{2}{*}{ Baseline } & \multirow[b]{2}{*}{ Postischemia } & \multicolumn{2}{|c|}{ Postreperfusion } \\
\hline & & & 6 hours & 12 hours \\
\hline \multicolumn{5}{|c|}{ BALF protein $(\mu \mathrm{g} / \mathrm{mL})$} \\
\hline \multicolumn{5}{|c|}{ Standard treatment } \\
\hline Graft & & $476.9 \pm 59.4$ & $1443.6 \pm 720.20^{*}$ & $1895.6 \pm 187.1 \dagger$ \\
\hline Native lung & $240.5 \pm 34.9$ & & $153.8 \pm 32.7$ & $501.9 \pm 167.7$ \\
\hline \multicolumn{5}{|c|}{ Surfactant treatment } \\
\hline Graft & & $393.7 \pm 97.8$ & $844.0 \pm 269.0$ & $1637.0 \pm 253.0 \dagger$ \\
\hline Native lung & $290.0 \pm 68.7$ & & $188.5 \pm 32.3$ & $447.4 \pm 123.1$ \\
\hline \multicolumn{5}{|l|}{ PMN in BALF $(\%)$} \\
\hline \multicolumn{5}{|c|}{ Standard treatment } \\
\hline Graft & & $1.8 \pm 0.6$ & $25.5 \pm 14.6$ & $82.0 \pm 7.3 \dagger$ \\
\hline Native lung & $1.8 \pm 0.7$ & & $28.8 \pm 4.3 \dagger$ & $30.0 \pm 6.7 \S$ \\
\hline \multicolumn{5}{|c|}{ Surfactant treatment } \\
\hline Graft & & $6.3 \pm 3.2$ & $36.0 \pm 15.1 \ddagger$ & $84.0 \pm 6.4 \dagger$ \\
\hline Native lung & $2.0 \pm 0.8$ & & $13.3 \pm 14.4$ & $23.0 \pm 13.8$ \\
\hline
\end{tabular}

$B A L F$, Bronchoalveolar lavage fluid; $P M N$, polymorphonuclear neutrophils.

Given are the mean \pm SEM of the BALF protein concentration (in $\mu \mathrm{g} / \mathrm{mL}$ ) and the neutrophil percentage (given in percentage of all cells, $\mathrm{n}=6$ lungs each). Baseline values were obtained from the excised left recipient lungs. Postischemia data originate from the donor right lungs, undergoing preservation but not transplantation. All other data refer to either the transplanted left lungs (graft) or the native recipient right lungs (native).

${ }^{*} P<.05$ in comparison to baseline values.

$\S P<.01$ in comparison to baseline values.

$\dagger P<.001$ in comparison to baseline values.

$\ddagger P=.08$ in comparison to baseline values.

Olympus, Hamburg, Germany) after 6 hours of reperfusion or in vitro by whole lung lavage excluding the upper lobes. In case of bronchoscopic lavage, the instrument was placed in wedge position in the upper lobe and the lavage was performed by repetitive injection and gentle aspiration of ten $20-\mathrm{mL}$ aliquots of sterile saline solution (recovery $\sim 60 \%$ ). For whole lung lavage, the main bronchus of the lower lobe was cannulated and fixed by a transbronchial suture, and lavage was done with $500 \mathrm{~mL}$ of sterile saline solution (recovery $\sim 70 \%$ ) by passive pressure gradients of $40 \mathrm{~cm} \mathrm{H}_{2} \mathrm{O}$. The lavage fluids were then filtered through sterile gauze, collected on ice, and immediately centrifuged at $200 \mathrm{~g}\left(4^{\circ} \mathrm{C}\right.$, 10 minutes) to separate cellular material. Protein content of this cell-free BALF was measured using a commercially available kit based on bicinchoninic acid. ${ }^{12}$ The remaining supernatant was aliquoted, frozen in liquid nitrogen, and stored at $-85^{\circ} \mathrm{C}$ until subsequent measurements.

\section{Statistics}

All results are reported as means \pm standard error of the mean (SEM) and were analyzed by a biostatistician (Moredata $\mathrm{GmbH}$, Giessen, Germany). Statistical analysis of differences between surfactant-treated lungs and controls was performed by testing principle significant diversity first (Kruskal-Wallis $H$ test), followed by comparison with a nonparameteric test (Mann-Whitney $U$ test). A Wilcoxon matched-pair test was used to compare baseline values with each time point.

\section{Results}

Storage of the Euro-Collins flushed lungs at $4^{\circ} \mathrm{C}$ for 24 hours did not result in a statistically significant rise of lavage protein or neutrophil contents, even if the protein levels were increased to a certain extent (Table 2). Similarly, the analysis of the wet-to-dry ratio did not detect significant lung fluid accumulation at the end of the preservation period (Figure 1, top). In contrast, after transplantation and reperfusion, a pronounced increase in pulmonary edema accumulation, lavage protein content, and the percentage of neutrophils within the alveolar cell population was noted (Table 2). This was evident both for the 6-hour and the 12-hour reperfusion period in the grafted lung. To some minor extent, however, protein leakage, neutrophil influx, and weight gain were also detected in the recipient's native lung. The percentage of neutrophils increased to $82.0 \% \pm 7.3 \%$ (mean \pm SEM) in the graft and to $30.0 \% \pm$ $6.7 \%$ in the native lungs within 12 hours of reperfusion, as compared with $<5 \%$ in controls. BALF protein levels were increased approximately fourfold in the graft and approximately twofold in the recipient's native lung 12 hour after onset of reperfusion (Table 2).

In the graft, the wet-to-dry ratio at the end of the reperfusion period (12 hours) was approximately doubled, and an approximately 1.7-fold increase in the wet-to-dry ratio was encountered in the native lungs (Figure 1, top). When applying the thermal dye dilution technique for characterization of the extravascular pulmonary content, a doubling of lung fluid was again noted in the transplanted and in the native lungs (Figure 1, bottom).

In parallel, the transplanted lungs developed a progressive decline of gas exchange and mechanical properties 


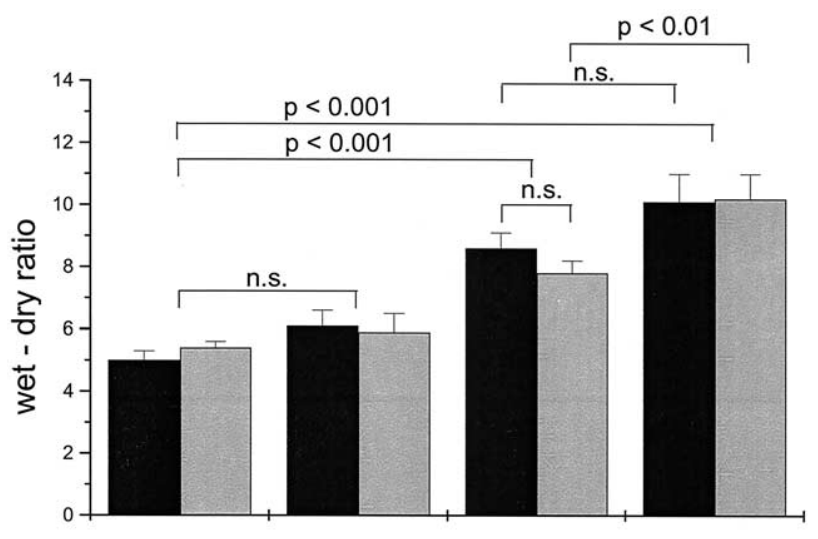

baseline preserved native lung graft

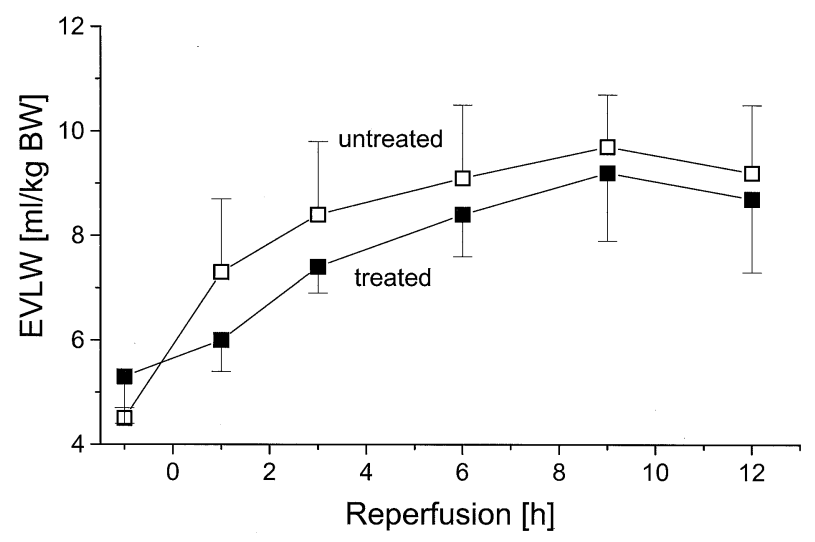

Figure 1. Wet-to-dry ratios (top) and extravascular lung water (bottom) in the time course of single lung transplantation. Wetto-dry ratios of the untreated left recipient lungs (baseline, originating from animals assigned to either the control or the surfactant group), the nontransplanted but Euro-Collins-preserved right donor lung (preserved, assessed at the end of the preservation period), the recipient right native lung (native lung, assessed 12 hours after transplantation), and the transplanted left lung (graft, assessed 12 hours after reperfusion) are given. Values are indicated for the control group (untreated, black column) and the surfactant-treated group (treated, gray column). Extravascular lung water (EVLW) was determined pre- and post-single lung transplantation in animals with (surfactant) or without (control) surfactant administration. n.s., not significant. Mean \pm SEM of 6 experiments.

under conditions of separate but synchronized mechanical ventilation. $\mathrm{PaO}_{2} / \mathrm{FIO}_{2}$ values (determined at an $\mathrm{FIO}_{2}$ of 0.5 after reperfusion) were $629.3 \pm 11.9 \mathrm{~mm} \mathrm{Hg}$ under baseline conditions, $253.5 \pm 15.1 \mathrm{~mm} \mathrm{Hg}$ at the onset of the reperfusion period, and dropped to $121.7 \pm 25.6 \mathrm{~mm} \mathrm{Hg}$ (6 hours) and $119.8 \pm 21.7 \mathrm{~mm} \mathrm{Hg}$ (12 hours) in the transplanted lungs (Figure 2). The graft's compliance was 19.5 $\pm 1.6 \mathrm{~mL} / \mathrm{mbar}$ after 1 hour of reperfusion and thus significantly reduced as compared with baseline conditions (40.2

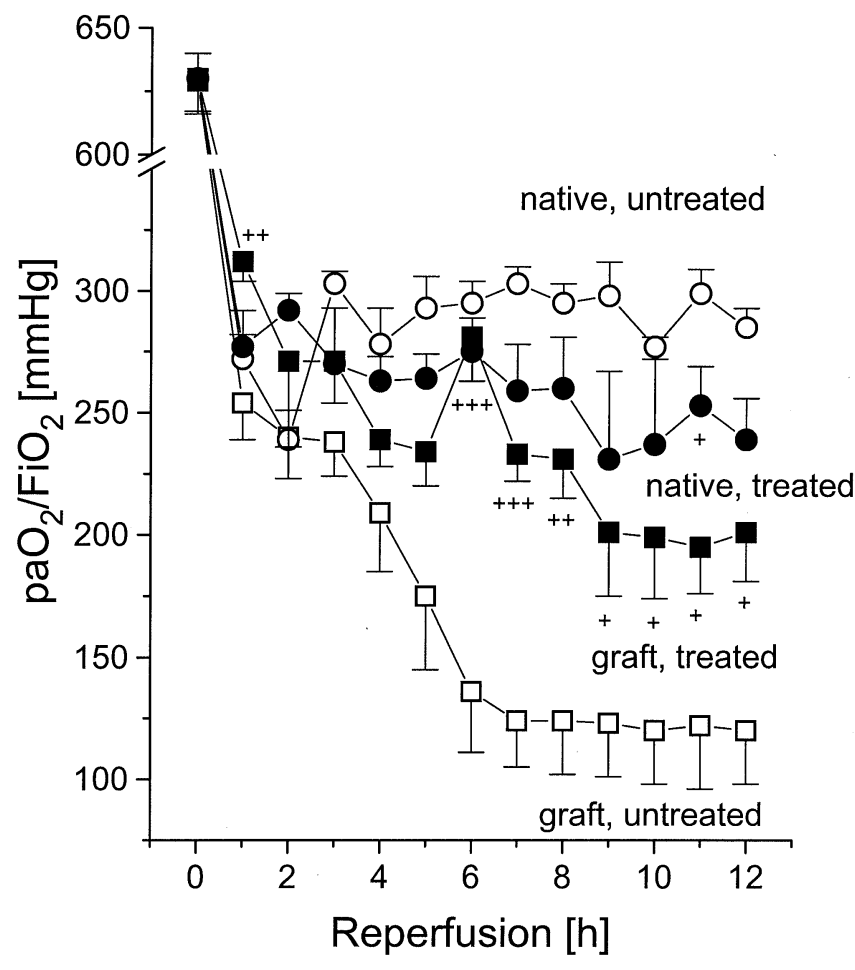

Figure 2. $\mathrm{PaO}_{2} / \mathrm{FiO}_{2}$ values in the pulmonary venous samples of the transplanted lung (graft, open sqaure) and the recipient's native lung (native, open circle). Data originate from animals receiving (treated, closed circle, closed square) or not receiving (untreated, open circle, open square) surfactant administration (mean \pm SEM of 6 lungs each). Significance level is indicated by $+P<.05$, $++P<.01$, or $+++P<.001$ for comparison between control group and surfactant group.

$\pm 5.8 \mathrm{~mL} / \mathrm{mbar}$ ), with a further decline to $11.5 \pm 1.6$ $\mathrm{mL} / \mathrm{mbar}$ at the end of the 12 -hour reperfusion period (Figure 3 ). In contrast to the graft, gas exchange and compliance of the recipient's native lung did not significantly decrease over this time span. However, as compared with the abovementioned baseline data, compliance values of the recipient's native lung were somewhat lower ( $27 \mathrm{~mL} / \mathrm{mbar})$ throughout the postoperative period. This was also true for the gas exchange conditions, in particular in the early postoperative phase, with subsequent gradual increase in the $\mathrm{PaO}_{2}$ values, which nearly approached baseline data at the end of the 12-hour observation period.

All 6 recipients of the control group were hemodynamically stable, not requiring any catecholamine support. As given in Table 3, CVP and PCWP did not change significantly. After reperfusion, a significant decrease in mean arterial pressure compared with baseline and compared with the surfactant-treated group was found in the control group (Table 3). In parallel, a less pronounced increase in CI compared with baseline values was detectable in both the control and surfactant group (Table 3). However, the de- 


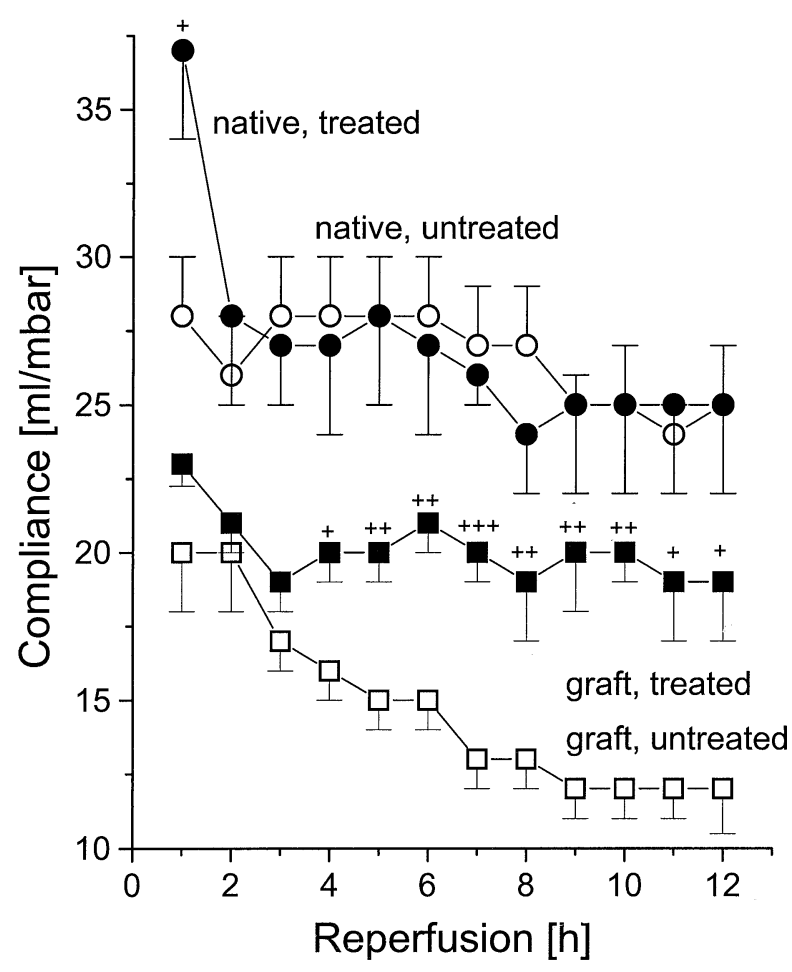

Figure 3. Dynamic lung compliance in animals undergoing single lung transplantation, analyzed separately for the transplanted lung (graft, open square) and the recipient's native lung (native, open circle). Data originate from animals receiving (treated, closed circle, closed square) or not receiving (untreated, open circle, open square) surfactant administration (mean \pm SEM of 6 lungs each). Significance level is indicated by $+P<.05,++P<$ .01 , or $+++P<.001$ ) for comparison between control group and surfactant group.

crease in systemic vascular resistance did not reach statistical significance (data not shown). The pulmonary arterial pressure and the transpulmonary gradient displayed significant higher values compared with baseline in the control group, but this did not reach statistical significance compared with the surfactant group (Table 3).

The bronchoscopic instillation of a bovine surfactant extract to the graft prior to ischemia (total dose $50 \mathrm{mg} / \mathrm{kg}$ BW) and to both the graft and the native lung upon start of reperfusion (total dose $200 \mathrm{mg} / \mathrm{kg} \mathrm{BW}$ ) resulted in a marked improvement of gas exchange and compliance in the transplanted lungs (Figures 2 and 3). After completion of the second surfactant administration, the compliance data of the graft were $23.0 \pm 0.5 \mathrm{~mL} / \mathrm{mbar}$, surpassing those in the non-surfactant-treated grafts. Moreover, stability of the compliance values of the grafts undergoing surfactant administration was noted over the subsequent 12 -hour reperfusion period, a feature significantly different from the control grafts. The $\mathrm{PaO}_{2} / \mathrm{FIO}_{2}$ values of the surfactant-treated grafts were $629.3 \pm 11.9 \mathrm{~mm} \mathrm{Hg}$ at the beginning and 201.2 $\pm 20.2 \mathrm{~mm} \mathrm{Hg}$ at the end of the reperfusion period, thus significantly surpassing the $\mathrm{PaO}_{2} / \mathrm{FIO}_{2}$ data of the nontreated transplanted controls. In contrast, the surfactant administration did not affect the pulmonary fluid accumulation (Figure 1, top and bottom), the neutrophil influx into the alveolar space, and the protein leakage into this compartment (Table 2).

\section{Discussion}

When analyzing the results of the current study, several aspects have to be discussed.

\section{Model Considerations}

In general, the presently used left lung transplantation model in dogs followed established techniques in the field. ${ }^{5,7,13,14}$ However, some important modifications were undertaken and comprised: first, the separate but synchronized ventilation of the graft and the native lung by using 2 ventilators working in the master/slave mode; second, the insertion of small catheters into the pulmonary veins of both lungs to obtain blood samples from each lung for blood gas analysis; and third, an immediate turn of the animals to the prone position upon termination of the surgical procedures. Such experimental setting ascertained (1) full control over volume and pressure applied to each lung, and, by this, (2) prevention of any gas volume shift between graft and native lung, (3) avoidance of clamping procedures of the large pulmonary arteries, and (4) restoration of physiological gravity forces on ventilation and perfusion distribution (prone position).

\section{Influence of Surfactant Administration on Pulmonary and Systemic Hemodynamics}

As anticipated from clinical ${ }^{15}$ and experimental ${ }^{16}$ data, a modest increase in pulmonary artery pressure and pulmonary vascular resistance was encountered in this single lung transplant model. This increase was not influenced by the surfactant treatment. This is in line with the previous observation that surfactant replacement improved gas exchange but did not affect pulmonary hemodynamics in patients with severe ARDS. ${ }^{2}$ Interestingly, however, the decline in systemic arterial pressure and vascular resistance, consistently noted in all transplanted animals, was only very transient and in the further course fully absent under conditions of surfactant administration. The underlying reasons for this phenomenon deserve further clarification.

\section{Influence of Surfactant Administration on Neutrophil Recruitment, Protein Leakage, and Pulmonary Edema Formation}

Lung surfactant has been implicated in the regulation of alveolar fluid homeostasis and both natural surfactant preparations, and single surfactant compounds were reported to suppress inflammatory activities of immunocompetent cells, 
TABLE 3. Hemodynamic variables in the animals undergoing lung transplantation

\begin{tabular}{|c|c|c|c|c|c|c|c|}
\hline & Baseline & 5 minutes & 1 hour & 3 hours & 6 hours & 9 hours & 12 hours \\
\hline $\begin{array}{l}\mathrm{Cl} \text { con. } \\
\text { (L/min) }\end{array}$ & $2.2 \pm 0.1$ & $3.3 \pm 0.3$ & $3.6 \pm 0.4$ & $2.9 \pm 0.0$ & $2.9 \pm 0.1$ & $2.9 \pm 0.3$ & $3.1 \pm 0.2$ \\
\hline $\begin{array}{l}\text { Cl surf. } \\
\text { (L/min) }\end{array}$ & $2.3 \pm 0.1$ & $2.8 \pm 0.3$ & $2.7 \pm 0.2$ & $3.0 \pm 0.2$ & $2.9 \pm 0.1$ & $3.5 \pm 0.3$ & $3.5 \pm 0.4$ \\
\hline $\begin{array}{l}\text { CVP con. } \\
\quad(\mathrm{mm} \mathrm{Hg})\end{array}$ & $5.8 \pm 0.7$ & $6.8 \pm 0.8$ & $5.0 \pm 1.0$ & $4.0 \pm 0.4$ & $4.4 \pm 0.3$ & $7.0 \pm 0.4$ & $6.8 \pm 0.7$ \\
\hline $\begin{array}{l}\text { CVP surf. } \\
\quad(\mathrm{mm} \mathrm{Hg})\end{array}$ & $6.3 \pm 1.1$ & $5.7 \pm 1.1$ & $6.3 \pm 1.4$ & $5.5 \pm 1.2$ & $5.8 \pm 1.7$ & $6.5 \pm 0.6$ & $6.7 \pm 0.9$ \\
\hline $\begin{array}{r}\text { PCWP con. } \\
(\mathrm{mm} \mathrm{Hg})\end{array}$ & $6.6 \pm 0.8$ & $5.8 \pm 0.5$ & $7.2 \pm 1.1$ & $5.9 \pm 0.6$ & $4.4 \pm 1.0$ & $7.2 \pm 0.5$ & $8.0 \pm 0.2$ \\
\hline $\begin{array}{l}\text { PCWP surf. } \\
(\mathrm{mm} \mathrm{Hg})\end{array}$ & $7.5 \pm 0.8$ & $7.3 \pm 1.1$ & $6.8 \pm 1.0$ & $6.0 \pm 1.0$ & $6.3 \pm 0.9$ & $8.3 \pm 0.6$ & $7.2 \pm 0.9$ \\
\hline $\begin{array}{l}\text { PAP con. } \\
\quad(\mathrm{mm} \mathrm{Hg})\end{array}$ & $14.6 \pm 1.3$ & $14.6 \pm 1.6$ & $13.2 \pm 1.3$ & $15.0 \pm 0.7$ & $15.0 \pm 1.7$ & $17.0 \pm 1.1$ & $19.5 \pm 1.4$ \\
\hline $\begin{array}{l}\text { PAP surf. } \\
(\mathrm{mm} \mathrm{Hg})\end{array}$ & $15.5 \pm 2.1$ & $15.8 \pm 1.2$ & $15.8 \pm 2.5$ & $17.8 \pm 0.7$ & $17.7 \pm 1.5$ & $20.7 \pm 1.0$ & $22.0 \pm 1.6$ \\
\hline $\begin{array}{l}\text { MAP con. } \\
\text { (mm Hg) }\end{array}$ & $72.2 \pm 3.0$ & $78.3 \pm 3.8$ & $67.8 \pm 3.5$ & $66.5 \pm 1.3$ & $70.8 \pm 3.6$ & $70.3 \pm 1.8$ & $64.6 \pm 2.5$ \\
\hline $\begin{array}{l}\text { MAP surf. } \\
\quad(\mathrm{mm} \mathrm{Hg})\end{array}$ & $81.5 \pm 6.4$ & $86.7 \pm 7.4$ & $77.8 \pm 3.0$ & $71.3 \pm 1.7$ & $82.3 \pm 1.3 \dagger$ & $85.8 \pm 4.3 \dagger$ & $88.8 \pm 6.4^{*}$ \\
\hline $\begin{array}{l}\text { TPG con. } \\
(\mathrm{mm} \mathrm{Hg})\end{array}$ & $8.0 \pm 0.5$ & $8.8 \pm 0.7$ & $8.0 \pm 0.6$ & $9.5 \pm 0.7$ & $11.0 \pm 0.7$ & $11.8 \pm 0.3$ & $11.0 \pm 1.1$ \\
\hline $\begin{array}{l}\text { TPG surf. } \\
\quad(\mathrm{mm} \mathrm{Hg})\end{array}$ & $9.0 \pm 0.7$ & $7.2 \pm 0.7$ & $6.7 \pm 0.6$ & $11.2 \pm 0.7$ & $11.2 \pm 0.5$ & $12.3 \pm 0.9$ & $12.0 \pm 1.0$ \\
\hline
\end{tabular}

$C l$, Cardiac index; con., control; surf., surfactant group; $C V P$, central venous pressure; $P C W P$, pulmonary capillary wedge pressure; $P A P$, pulmonary arterial pressure; $M A P$, mean arterial pressure; TPG, transpulmonary pressure gradient (difference between mean pulmonary artery pressure and capillary wedge pressure).

${ }^{*} P<.05$, comparison between control and surfactant group.

$\dagger P<.01$, comparison between control and surfactant group.

including free radical production by alveolar macrophages and monocytes, macrophage migration, and lymphocyte proliferation. ${ }^{17,18}$ However, in the present study, edema formation, protein leakage into the alveolar space, and neutrophil migration into this compartment were not significantly affected by bronchoscopic surfactant administration, though this approach established near-physiological surfactant function in the transplanted lungs. This is in line with a previous study of Novick and colleagues, ${ }^{5}$ in which surfactant instillation prior to ischemia alone or in combination with surfactant instillation after reperfusion caused only very minor (nonsignificant) reduction of reperfusion-related protein leakage. In contrast to the surfactant instillation alone, after combined therapy with aerosolized and instilled surfactant preparations the reduction in intra-alveolar protein content was more pronounced. Probably the technique of treatment has an impact on the permeability for serum proteins. $^{13}$

Interestingly, neutrophil influx and plasma protein leakage also occurred to some very minor extent in the native lungs of animals undergoing single lung transplantation. In previous transplantation studies with combined lung ventilation, ${ }^{5,14,19}$ the increase in BALF protein levels in the native lungs, observed after the reperfusion period, nearly approximated that in the transplanted lungs, irregardless of the length of the ischemia period (1.5-36 hours) or the mode of ischemia (warm vs cold). It is tempting to speculate that the prevention of hyperinflation of the native lungs due to the mode of separate lung ventilation was the predominant underlying reason for the maintenance of near-physiological function including barrier properties in the native lungs in the present study.

\section{Improvement of Mechanics and Gas Exchange after Bronchoscopic Surfactant Administration}

A progressive impairment in gas exchange and loss of lung compliance were noticed in the graft, but not in the recipient's native lung. In accordance with previous investigations in the field, changes in surface activity and gas exchange were tightly linked, as suggested by the highly significant correlation between minimum surface tension and $\mathrm{PaO}_{2}$ in the transplanted lungs (see Figure 4).

As could have been anticipated on the basis of these data, both the compliance values and the gas exchange data of the transplanted lungs were markedly improved under conditions of bronchoscopic surfactant administration. This finding supports previous investigations, which similarly showed a beneficial impact of surfactant on arterial oxygen- 


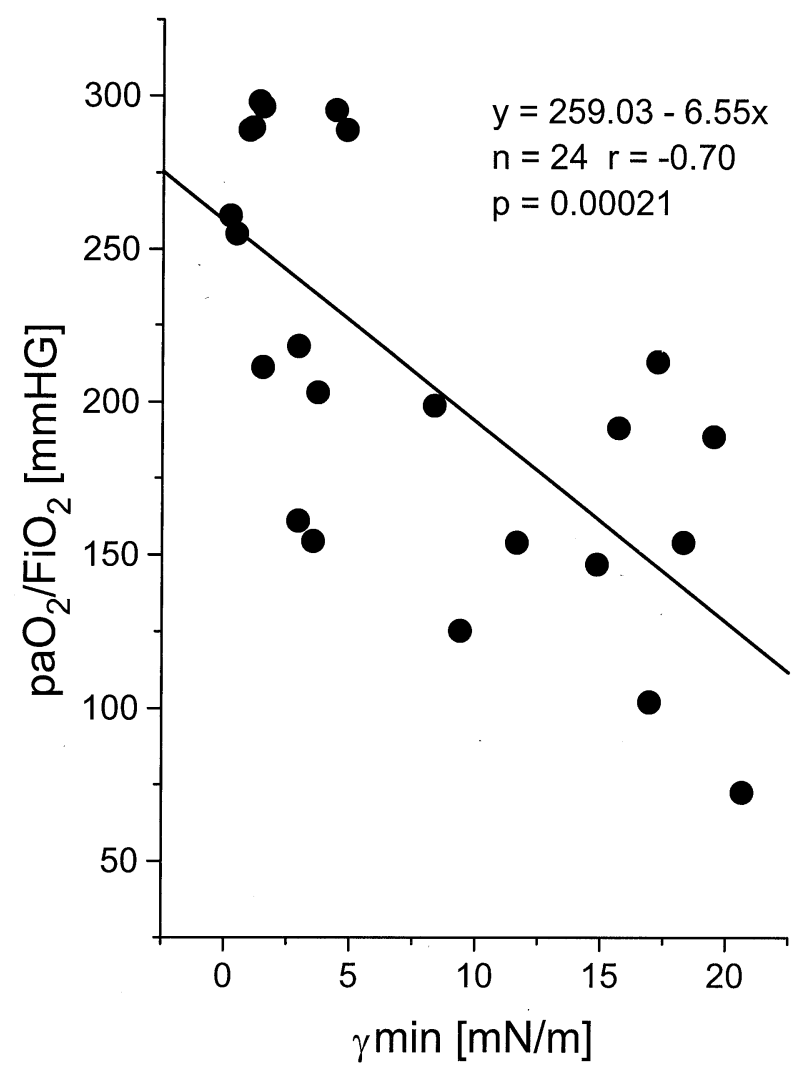

Figure 4. Correlation of $\mathrm{PaO}_{2} / \mathrm{FiO}_{2}$ values with surface activity, as assessed with the pulsating bubble surfactometer. Given are the data pairs of the controls and the graft in absence of surfactant therapy. BALF samples were taken from the control group prior transplantation and 6 and 12 hours after reperfusion respectively.

ation in experimental lung transplantation. ${ }^{4,8,13,20}$ The present study adds an important piece of knowledge to this field because it shows that indeed such effect is due to a direct impact of the exogenous surfactant material on the reperfused lungs, which are ventilated in a controlled fashion independent of the native lung. This observation does not exclude the possibility that surfactant administration might additionally influence the development of VILI in the nontransplanted lung, which may occur under conditions of combined ventilation and which was excluded by the current experimental protocol. Such view is supported by the data of Novick and coworkers, ${ }^{5}$ who observed marked impairment of the native lung's gas exchange in a canine model of ischemia and reperfusion, as suggested by blood gas analysis upon left pulmonary artery snaring ${ }^{14}$ or, indirectly, blood gas data obtained from arterial source reflecting both lungs. Noteworthy, the marked beneficial effect of surfactant administration on compliance and gas exchange in the transplanted lungs in the present study was noted under prone positioning of the animals, which should provide the best possible physical conditions for ventilation- perfusion matching, and under PEEP ventilation, employed to prevent atelectasis formation. The currently applied total dose of $250 \mathrm{mg}$ surfactant per kilogram BW is well in line with preceding studies of surfactant administration in ARDS models and is based on the knowledge that surfactant inhibitory mechanisms based on protein leakage and inflammatory mediator generation are to be overcome by the exogenous surfactant material (see companion article ${ }^{9 a}$ ). With this dose being administered in part before onset of ischemia $(50 \mathrm{mg} / \mathrm{kg})$ and in part immediately upon reperfusion $(200 \mathrm{mg} / \mathrm{kg})$, the dissociation of the $\mathrm{PaO}_{2}$ curves of the surfactant-treated and the control grafts already commenced within 1 hour of reperfusion.

\section{VILI of the Native Lung under Experimental Conditions}

Involvement of the native lung during reperfusion injury (remote injury) is well known under clinical conditions and is thought to be related to blood-borne mediators that are released by the reperfused donor lung. In addition, most entities being associated with the need for lung transplantation (eg, idiopathic pulmonary fibrosis, cystic fibrosis) are known for far-reaching alterations of the surfactant properties. In these cases, a donor lung originating from a healthy donor and thus having good surface tension-reducing properties is transplanted into a patient who has a native lung with increased alveolar surface tension. If ventilated jointly after reperfusion, the donor might be preferentially ventilated due to its better compliance, and, if reperfusion injury develops, surface tension properties might align and distribution of minute ventilation might be similar between both lungs. In experimental models of lung transplantation, however, matters might be significantly different. In this experiment, a donor organ originating from a healthy lung but being held under (mostly prolonged) ischemic conditions is transplanted into a healthy recipient with a healthy contralateral lung. This native lung, as again shown in the companion article, ${ }^{9 \mathrm{a}}$ must be expected to have good surface tension-reducing properties. Due to the very good compliance, this native organ might thus be very susceptible to the deleterious effects of high tidal volume ventilation and thus VILI, once reperfusion injury develops in the graft and if jointly ventilated with the graft. It is in this line of reasoning that in a model of experimental lung transplantation, ${ }^{14}$ marked changes of gas exchange, surface tension, and surfactant composition were noted early also in the native organ. Actually, these authors did not find a difference in $\mathrm{PaO}_{2}$ values between the transplanted organ versus the native lung. In another paper addressing also surfactant properties after single lung transplantation in $\operatorname{dogs},{ }^{7}$ it was found that the small-to-large surfactant aggregate ratio was even higher in the native lung as compared with the graft 6 hours after reperfusion. In our present study, we were unable to detect a relevant reduction in functional properties of the 
native lung under separate but synchronized ventilation. Apart from an increase in extravasal water accumulation, the loss of permeability was not extended and a significant leakage of plasma proteins or a transmigration of neutrophils into the alveolar space did not occur.

VILI may substantially contribute to the severity of ARDS, as suggested from a recent multicenter trial. ${ }^{21}$ In fact, severe lung injury including neutrophil transmigration, systemic and alveolar cytokine release, impairment of surfactant function, disturbance of gas exchange, and loss of lung compliance may experimentally be provoked by ventilating otherwise healthy lungs with inappropriately high tidal volume. ${ }^{22}$ A further study of Novick and colleagues ${ }^{7}$ addressed the capability of bovine surfactant preparations to improve the function of ventilator-injured donor lungs in order to improve the donor pool. Otherwise healthy donor lungs subjected to mechanical ventilation with high tidal volumes showed decreased oxygen tension, increased intraalveolar protein content, and a significant deterioration of the surfactant composition. After surfactant treatment a restoration of lung function and surfactant properties could be achieved. ${ }^{7}$ In view of these new insights into the impact of respirator therapy on the progression of acute lung injury, we employed separate but synchronized ventilation of the graft and the native lung. By this, we think, we avoided volume shift and thus hypoventilation of the transplanted organ graft on the one hand and overinflation of the native lung on the other hand. Moreover, this approach ascertained adequate assessment of the gas exchange properties of each lung, with mismatch of volume distribution between the 2 different organs in the single lung-transplanted animals being prevented.

\section{Conclusion}

In concert with the finding that the ex vivo surfactant properties are seriously impaired in the transplanted lungs but not in the native recipient's lungs (see companion article $^{9 a}$ ), the beneficial effect of bronchoscopic surfactant administration on arterial oxygenation and compliance of the graft further supports the view that surfactant abnormalities substantially contribute to the disturbances of gas exchange and the loss of compliance in reperfused lungs. Surfactant administration, whether undertaken via bronchoscopy as currently performed or via different delivery techniques (instillation, aerosolization), thus presents a new therapeutic approach for improving posttransplantation graft function. Future studies should address the question whether such surfactant administration is most appropriately undertaken prior to ischemia, both prior to ischemia and in the early postreperfusion period as presently performed, or in a later phase of reperfusion injury.

\section{References}

1. Khan SU, Salloum J, O'Donovan PB, et al. Acute pulmonary edema after lung transplantation: the pulmonary reimplantation response. Chest. 1999;116:187-94.
2. Gregory TJ, Steinberg KP, Spragg R, et al. Bovine surfactant therapy for patients with acute respiratory distress syndrome. Am J Respir Crit Care Med. 1997;155:1309-15.

3. Novick RJ, Possmayer F, Veldhuizen RA, Menkis AH, McKenzie FN. Surfactant analysis and replacement therapy: a future tool of the lung transplant surgeon? Ann Thorac Surg. 1991;52:1194-200.

4. Erasmus ME, Petersen AH, Hofstede G, Haagsman HP, Bambang Oetomo S, Prop J. Surfactant treatment before reperfusion improves the immediate function of lung transplants in rats. Am J Respir Crit Care Med. 1996;153:665-70.

5. Novick RJ, Veldhuizen RA, Possmayer F, Lee J, Sandler D, Lewis JF. Exogenous surfactant therapy in thirty-eight hour lung graft preservation for transplantation. J Thorac Cardiovasc Surg. 1994;108:259-68.

6. Novick RJ, Gehman KE, Ali IS, Lee J. Lung preservation: the importance of endothelial and alveolar type II cell integrity. Ann Thorac Surg. 1996;62:302-14.

7. Novick RJ, Gilpin AA, Gehman KE, et al. Mitigation of injury in canine lung grafts by exogenous surfactant therapy. $J$ Thorac Cardiovasc Surg. 1997;113:342-53.

8. Hohlfeld JM, Struber M, Ahlf K, et al. Exogenous surfactant improves survival and surfactant function in ischaemia-reperfusion injury in minipigs. Eur Respir J. 1999;13:1037-43.

9. Nonaka M, Kadokura M, Takaba T. Effects of initial low flow reperfusion and surfactant administration on the viability of perfused cadaveric rat lungs. Lung. 1999;177:37-43.

9a.Günther A, Balser M, Schmidt R, Markart P, Olk A, Börgermann J, et al. Surfactant abnormalities after single lung transplantation in dogs: impact of bronchoscopic surfactant administration. J Thorac Cardiovasc Surg. 2004;127:344-54.

10. Ito Y, Veldhuizen RA, Yao LJ, McCaig LA, Bartlett AJ, Lewis JF. Ventilation strategies affect surfactant aggregate conversion in acute lung injury. Am J Respir Crit Care Med. 1997;155:493-9.

11. Neumann P. Extravascular lung water and intrathoracic blood volume: double versus single indicator dilution technique. Intensive Care Med. 1999;25:216-9.

12. Gunther A, Siebert C, Schmidt R, et al. Surfactant alterations in severe pneumonia, acute respiratory distress syndrome, and cardiogenic lung edema. Am J Respir Crit Care Med. 1996;153:176-84.

13. Novick RJ, MacDonald J, Veldhuizen RA, et al. Evaluation of surfactant treatment strategies after prolonged graft storage in lung transplantation. Am J Respir Crit Care Med. 1996;154:98-104.

14. Veldhuizen RA, Lee J, Sandler D, et al. Alterations in pulmonary surfactant composition and activity after experimental lung transplantation. Am Rev Respir Dis. 1993;148:208-15.

15. Kemming GI, Merkel MJ, Schallerer A, et al. Inhaled nitric oxide (NO) for the treatment of early allograft failure after lung transplantation. Munich Lung Transplant Group. Intensive Care Med. 1998;24:1173-80.

16. Brinkmann M, Borgermann J, Splittgerber FH, et al. Pulmonary blood flow is inhomogeneously reduced after Euro Collins-preservation and lung transplantation. Ann Thorac Surg. 2002;73:226-32.

17. Hayakawa H, Myrvik QN, St Clair RW. Pulmonary surfactant inhibits priming of rabbit alveolar macrophage. Evidence that surfactant suppresses the oxidative burst of alveolar macrophage in infant rabbits. Am Rev Respir Dis. 1989;140:1390-7.

18. Kremlev SG, Umstead TM, Phelps DS. Effects of surfactant protein A and surfactant lipids on lymphocyte proliferation in vitro. Am J Physiol. 1994;267:L357-64.

19. Watanabe A, Kawaharada N, Kusajima K, Komatsu S, Takahashi H. Contralateral lung injury associated with single-lung ischemia-reperfusion injury. Ann Thorac Surg. 1996;62:1644-9.

20. Hausen B, Rohde R, Hewitt CW, et al. Exogenous surfactant treatment before and after sixteen hours of ischemia in experimental lung transplantation. J Thorac Cardiovasc Surg. 1997;113:1050-8.

21. ARDS-Network-2000. Ventilation with lower tidal volumes as compared with traditional tidal volumes for acute lung injury and the acute respiratory distress syndrome. The Acute Respiratory Distress Syndrome Network. N Engl J Med. 2000;342:1301-8.

22. Slutsky AS. Lung injury caused by mechanical ventilation. Chest. 1999;116:9S-15S. 